\title{
AN INVESTIGATION OF DROUGHT AROUND CHI WATERSHED DURING TEN-YEAR PERIOD USING TERRA/MODIS DATA
}

\author{
Tanutdech ROTJANAKUSOL ${ }^{1}$, Teerawong LAOSUWAN ${ }^{2}$ *
}

DOI: 10.21163/GT_2019.142.07

\begin{abstract}
:
To examine the drought affected area is highly challenging because the drought is a natural disaster that starts and expands slowly. The severity of the drought is different when the rainfall is imbalance in the area. The objective of this study was to analyze the drought around Chi watershed with total area of $49,131.920 \mathrm{~km}^{2}$ by using data from Terra/MODIS satellite during 10 years (2007-2016). On part of method operation, the NDVI data was obtained from Terra/MODIS satellite, and VCI (Vegetation Condition Index) analysis was performed to examine the condition of plants which could identify the condition of drought in the area. According to the study, it was found that in 2015, it was the time when the drought affected area was at most which was equal to 91.54 percent, or $44975.23 \mathrm{~km}^{2}$. When the analysis results of these ten years were brought to find relationship with rainfall, it was found that the decision coefficient was $\mathrm{R}^{2}=0.913$. It can be concluded from the results of this study that VCI could be used as indicator and could identify the drought in Chi watershed in terms of area and time reasonably.
\end{abstract}

Key-words: Drought, Remote Sensing, Chi Watershed, NDVI, VCI

\section{INTRODUCTION}

Drought is one of the top disasters of Thailand that cause considerable damage especially against the agriculture and cultivation due to the geography and weather that are risk factors of drought (Gomasathit rt al., 2015; Laosuwan et al., 2016). The Chi watershed, located at the northeastern region of Thailand, has been affected by drought for a very long period of time; this is considered as one major problem which is mainly caused by rainfall and other related factors including the absorption of soil, the water source on the ground, the water source under the ground, and the use of land (Uttaruk \& Laosuwan, 2017). The drought is caused by an absence of rain during rainy season during June to July. According to the analysis into the pattern of rain in terms of area and time, it was found that an absence of rain also happens after September as well, especially in Chi watershed which is highly affected by drought since it is the area where the southwestern monsoon could not reach to; also, if there is no tropical hurricane moving through in a certain year, there would be more severe drought (Rotjanakusol \& Laosuwan, 2018). The consequence from drought was a lack of consumable water to be used in various activities, especially in agriculture which is the main career of the people living around Chi watershed; also, it would have an impact on people's consumption. Therefore, a lack of water would severely affect the

\footnotetext{
${ }^{1,2}$ Department of Physics, Faculty of Science, Mahasarakham University, Khamriang Sub-District, Kantarawichai District, Maha Sarakham,44150,Thailand, tanutdech.r@msu.ac.th, teerawong@msu.ac.th, *Corresponding author
} 
cultivation - it decreases the agricultural plants thus leading to economic, social, and environmental problems (Bordi \& Fraedrich, 2009; Wang et al.,2014).

The study to try to understand the characteristics of drought therefore becomes vital, and must be done for the benefit in providing advance precaution to those concerned, and there would be a plan to solve the problems (Fensham \& Holman, 1999; Gebrehiwot et al., 2011). In analyzing the drought, a wide variety of data are used including rainfall, moisture of the soil, the evaporation of water. Often, there is no comprehensive data for the whole area that would affect the quality of the analysis result in a particular area (Lines et al., 2017). The data obtained from satellite thus is used to analyze the drought since it is the source of data that can store data continuously, covering the vast area and could be used to identify the location also (Furtuna \& Holobaca, 2013; Chang et al., 2018; Nistor et al., 2018; Son et al., 2018; Canedo-Rosso et al., 2019). The word "drought" has no universal clear definition; it is just the period of time when the climate is dried and affects the change of plants and moisture in soil. The growth of plants is the direct key indicator for the analysis of drought (Tucke, 1979; Wang et al., 2003; Dutta et al., 2015; Jiao et al., 2016; Rimkus et al., 2017). With such reasons, the objective of this study, consequently, focuses on the analysis of drought and the assessment for drought in Chi watershed by using data from Terra/MODIS satellite during 10 years (2007-2016).

\section{AREAS AND DATA}

\subsection{Study area}

The Chi watershed is located at the northeastern region of Thailand (Fig.1); it is located between the $15^{\circ} 30^{\prime}$ north latitude to $17^{\circ} 30^{\prime}$ north latitude, and is between the $101^{\circ} 30^{\prime}$ east longitude to $104^{\circ} 30^{\prime}$ longitude, with total area of $49,131.920 \mathrm{~km}^{2}$, with average temperature in the whole year of $26.9{ }^{\circ} \mathrm{C}$, with maximum temperature in April of $35.9^{\circ} \mathrm{C}$, and minimum temperature in December of $16.9{ }^{\circ} \mathrm{C}$, with annual average rainfall of $1,231 \mathrm{~mm}$.

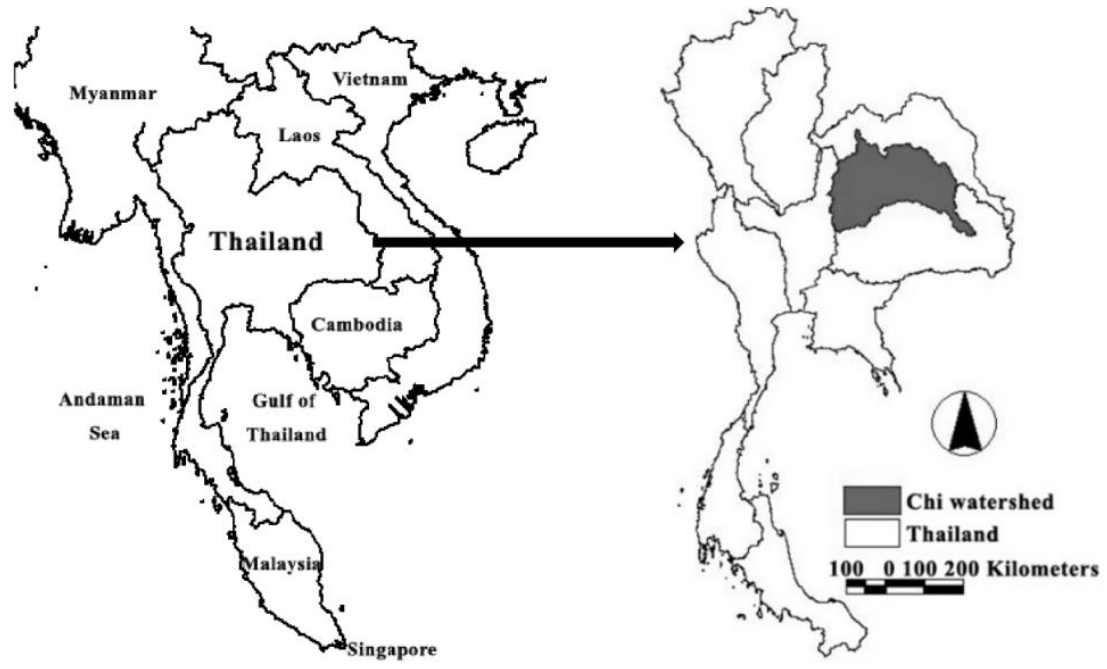

Fig. 1. Study area. 


\subsection{Data}

\subsubsection{Satellite data}

Terra/MODIS satellite was designed to be used in exploring and monitoring natural resources data on earth, with the width of swath of about $2,330 \mathrm{~km}^{2}$, with spatial resolution ranging from $250 \mathrm{~m}$ to $1000 \mathrm{~m}$, with data recording system of 36 wavelengths (Xiong et al., 2009). Therefore, data from Terra/ MODIS satellite are appropriate in monitoring change in vast area like Chi watershed. In this study, MOD13Q1 product dataset (Tab. 1) was collected in vegetation indices from Terra/MODIS satellite during Augusts of 2007 to 2016 (10 years); subsequently, the geometric correction was done by adjusting the reference coordinates to be in WGS84-UTM zone $48 \mathrm{~N}$ system; the pixels were assessed by nearest neighbor method, and data from Terra/MODIS satellite were subset by using boundary line of Chi watershed.

Table 1.

\section{Characteristics of MOD13Q1.}

\begin{tabular}{cc}
\hline Characteristic & Description \\
\hline Temporal Granularity & 16 -Day \\
Temporal Extent & February 2000 - Present \\
Spatial Extent & Global \\
Coordinate System & Sinusoidal \\
Geographic Dimensions & $1200 \mathrm{~km} \mathrm{x} \mathrm{1200} \mathrm{km}$ \\
Pixel Size & $250 \mathrm{~m}$ \\
SDS Name & NDVI \\
\hline
\end{tabular}

\subsubsection{Rainfall data}

In this study, monthly rainfall data measured from ground rainfall measuring stations located in Chi watershed of Thai Meteorological Department (TMD) were collected. These monthly rainfall data would be used in finding the statistical relationship with analysis results from Terra/MODIS satellite data further.

\section{METHODOLOGY}

In this study, the procedures in analyzing data were determined as shown in Fig. 2, with details of operation as follows:

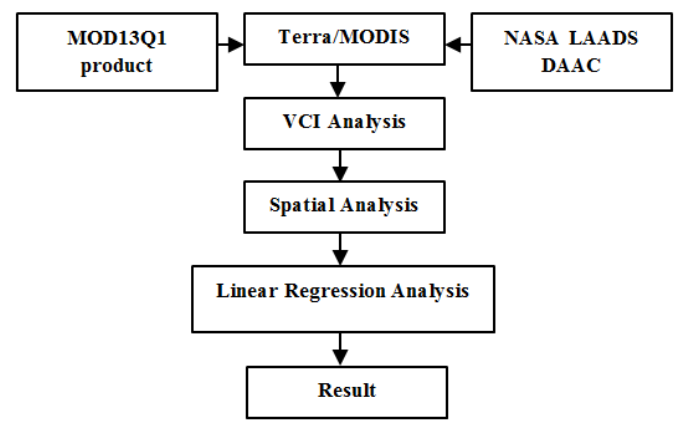

Fig.2. Implementation procedures. 


\subsection{Vegetation Condition Index (VCI) Analysis}

Since VCI is the value developed from NDVI, in the study the data from Terra/MODIS of 16 days and MOD13Q1 product set were used. Data used from this product was NDVI indices which are beneficial indicators and are widely used in the inspection of plant changes. NDVI is the calculation from ratio between difference and sum total of reflection of Red wavelength and NIR wavelength of objects on earth. NDVI of between -1 to +1 would be obtained from the calculation. In the area covered by plants, the reflective value in NIR wavelength would be higher than that in Red wavelength, thus making the NDVI value to be positive, whereas the soil surface, the open area, and the construction area would have similar reflective value between these two wavelengths thus making NDVI value to approach near zero (Park et al., 2008; Rotjanakusol \& Laosuwan, 2019). In the case of water surface, the reflective value in NIR wavelength would be lower than Red wavelength thus making NDVI value to be negative (Thavorntam et al., 2015). The method in calculating NDVI is shown in Equation 1. For VCI, it would be the adjustment of NDVI to be brighter by using maximum and minimum values of NDVI to be used in the calculation where the VCI value would vary between 0 to 100 ; this would be related to the change of plant condition from the least to the most value. VCI can be shown as in Equation 2.

$$
N D V I=\frac{N I R-R E D}{N I R+R E D}
$$

Where;

$N I R=$ Near Infrared Band

$R E D=$ Red band

$$
V C I=\frac{N D V I-N D V I_{\min }}{N D V I_{\max }-N D V I_{\min }} \times 100
$$

Where;

$N D V I_{\text {max }}=$ Maximum NDVI at study time of each pixel

$N D V I_{\text {min }}=$ Minimum NDVI at study time of each pixel.

\subsection{Spatial analysis}

The spatial analysis of drought is the classification of levels of plants conditions during Augusts of each year (2007-2016). In this study, the VCI drought levels were divided into 5 levels (Tab. 2) with 0-20 score meaning the worst condition of plants (very high drought) to 80-100 score meaning best condition of plants (very low drought).

Table 2.

VCI drought levels.

\begin{tabular}{cc}
\hline Level & VCI \\
\hline $00.00-20.00$ & very high drought \\
$21.00-40.00$ & high drought \\
$41.00-60.00$ & moderate drought \\
$61.00-80.00$ & low drought \\
$81.00-100.00$ & very low drought \\
\hline
\end{tabular}




\subsection{Analysis of relationship between VCI and rainfall}

The analysis of relationship between VCI and rainfall is divided into 2 forms including 1) the analysis into statistical relationship - the VCI analysis result from Item 3.2 and rainfall data collected from TMD would be used to find statistical relationship in form of Linear Regression Analysis, 2) the analysis of change in terms of time by comparing data between VCI and rainfall during Augusts of each year (2007-1016).

\section{RESULTS AND DISCUSSIONS}

\subsection{VCI analysis result}

As mentioned above, VCI value is the value developed from NDVI. The result of NDVI analysis obtained from Terra/MODIS satellite (MOD13Q1) can be shown in Fig.3. For the NDVI analysis, it can be concluded that the maximum, the minimum, the means, and the standard deviation of NDVI during Augusts of each year (2007-2016) in each period of time reveal the different conditions of plants; the NDVI means could identify the condition of plants or drought in each year. According to the NDVI analysis result, it was found that the minimum means was 0.196 in 2015 and the maximum means was 0.314 in 2013.

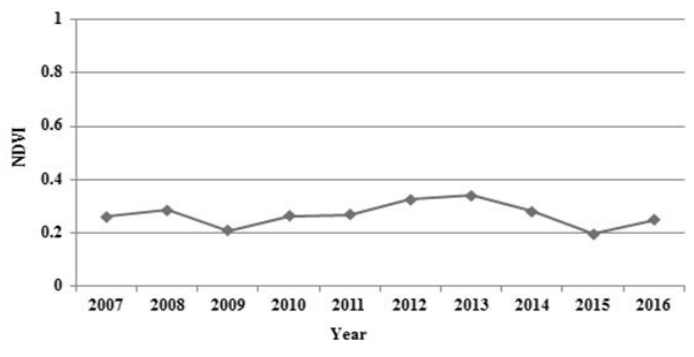

Fig.3. NDVI result.

For the VCI analysis result, it was found that the means could identify the condition of plants or drought during Augusts of each year with minimum means of 24.015 in 2015 and maximum means of 91.635 in 2013. The VCI means data in 10 years can be concluded in Fig. 4, with graph showing the variance of VCI in each year, depending on the condition of plants and rainfall.

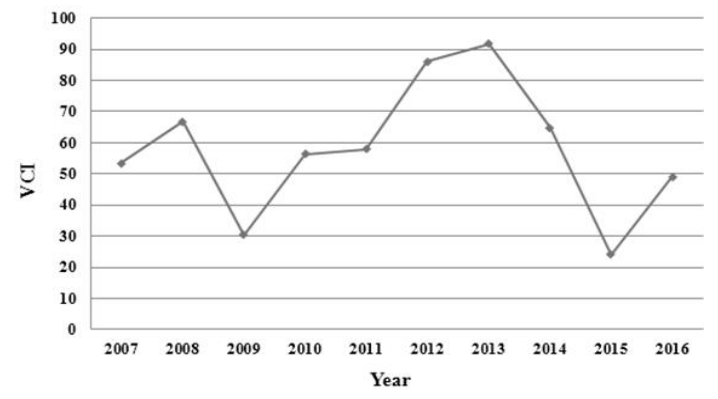

Fig.4. VCI result. 


\subsection{Spatial analysis result}

The spatial analysis result during Augusts of each year reveal the different conditions of plants of $0-100$ scores; such scores is consistent with the theory, where the means can identify the condition of plants or drought in each year. The spatial analysis result in this study can be shown in Fig. 5 .

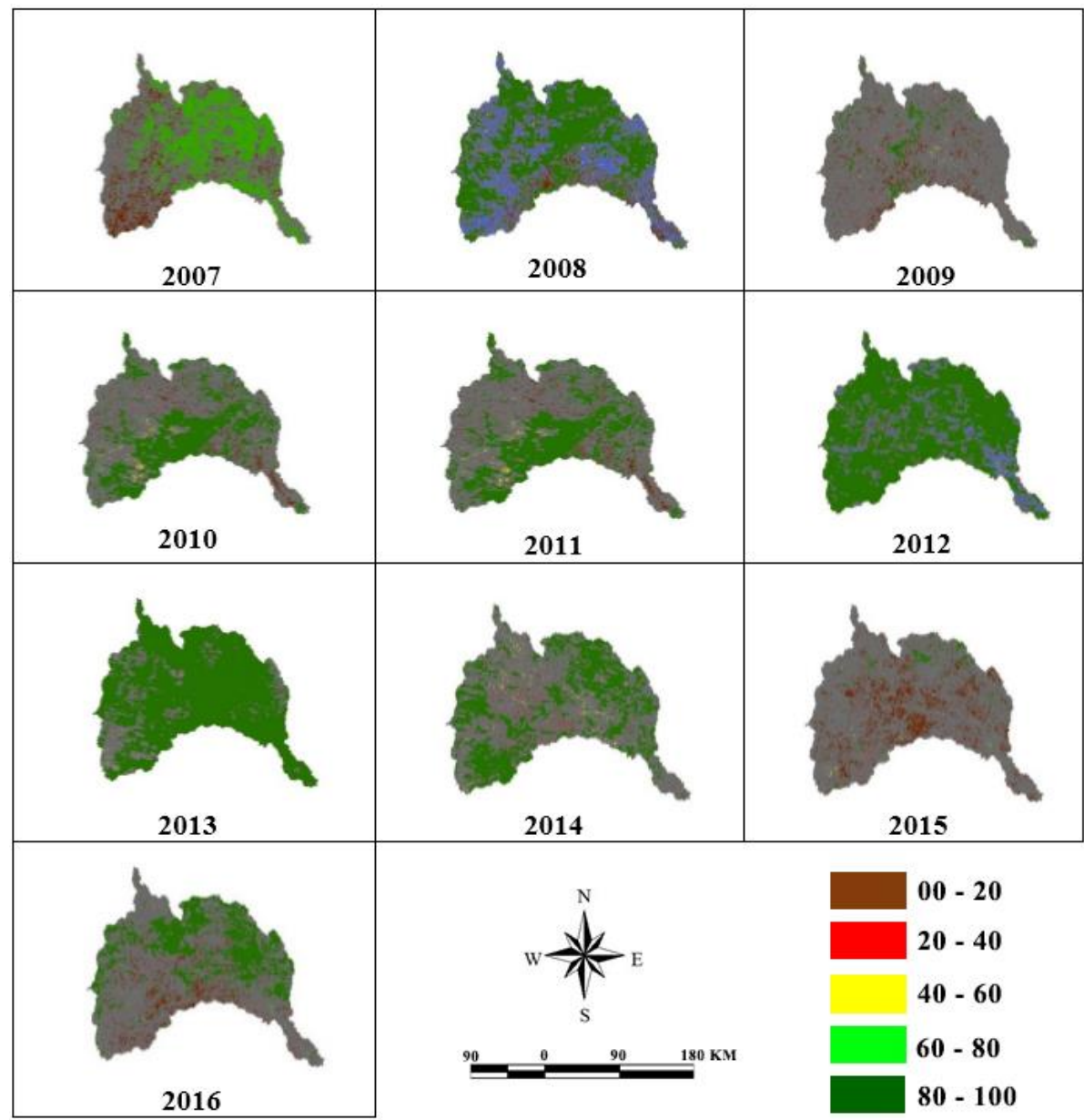

Fig.5. Spatial analysis.

According to Fig. 5, it was found that in the area in Chi watershed in northeastern region of Thailand in 2007, 2008, 2010, 2011, 2014, and 2016, the condition of plants was at moderate level, signifying that during such period, the Chi watershed was moderately affected by drought. In 2009 the condition of plants was low and was lowest in 2015, signifying that the drought was at much and most level, respectively. And in 2012, there condition of plants was high and highest in 2013, pointing out that the drought was little and least respectively. Besides, the researcher had brought the VCI spatial analysis result to perform analysis in percentage of drought as shown in Fig. 6. 


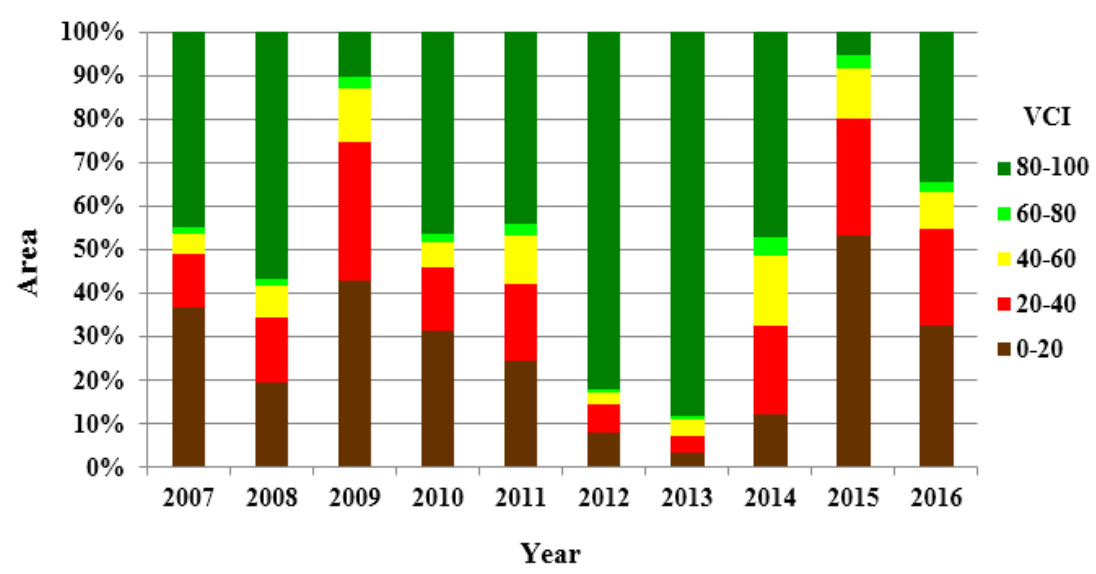

Fig.6. Percentage of drought.

According to Fig.6, it was found that in 2015 the drought was most level, with the level of very low drought of 53.303 percent or equal to $26,188.794 \mathrm{~km}^{2}$, and the drought of low level equal to 26.983 percent or the area of $13,257.251 \mathrm{~km}^{2}$, and the moderate drought equal to 11.254 percent or the area of $5529.187 \mathrm{~km}^{2}$, reflecting the clear condition of drought of Chi watershed.

\subsection{Result of analysis of relationship between VCI and rainfall Spatial analysis result}

\subsubsection{Analysis result of statistical relationship}

The analysis result of relationship between VCI (independent variable) and rainfall (dependent variable) during Augusts of each year (2007-2016) was found that the change of VCI is consistent with the rainfall; the analysis result of relationship is shown in Fig. 7. From the Fig. 7, the result of analysis into the relationship between VCI and the rainfall lead to the equation of $y=0.1839 x+186.64$, and with decision of coefficient of $R^{2}=0.913$; the coefficient is near 1, showing that the relationship is of high level. It can be explained that if in August of any year, the VCI is of high level, then the rainfall measured would be of high level accordingly; on the contrary, if VCI is little, the rainfall measured would be little accordingly as well.



Fig.7. Relationship between VCI and the rainfall. 


\subsubsection{Analysis results of change in terms of time}

The result of analysis into change in yearly term of VCI and rainfall in this study was that the change in terms of time of VCI means was consistent with the rainfall; however, the change of VCI may be changed more slowly than that of the rainfall since the plants were developed after there was sufficient amount of water for the growth. The change of VCI and the rainfall in 2015 would be lowest, and in was found that in 2013, the VCI and the rainfall was highest; the result of analysis of change on yearly basis of VCI and the rainfall is shown in Fig. 8.

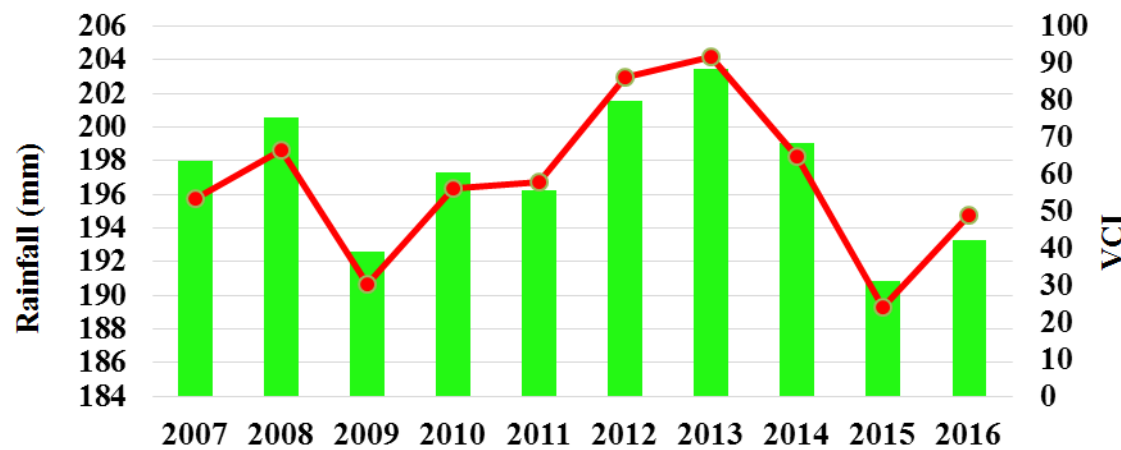

Year

Rainfall (mm) $\longrightarrow$ VCI

Fig. 8. The result of analysis into change in yearly term of VCI and rainfall.

\section{CONCLUSIONS}

The drought in Thailand directly affects the agriculture and water source since Thailand is the country where the people do farming especially growing rice; also, Thailand is considered as one of the largest field of rice production in the world. Mostly, the drought in Chi watershed that directly affects agriculture occurs in rainy season where the rainfall is absent for an extended period of time. In this study, the focus was on drought and the assessment for drought in Chi watershed by using data from Terra/MODIS satellite during Augusts in 10 years (2007-2016). The reason why it is such period of time is that under the calendar, the main agricultural cultivation of Thailand such as rice (wet season rice), oily plant (soybean, green bean and peanut), field plant (corn for feeding animals), would grow with fully green leave (The Department of Agricultural Extension, 2017); if in such month of any year, the agricultural plants grow with many green leaves compared with all area, it would mean that the drought is little, on the contrary, if the agricultural plants grow with just a few green leaves compared with all area, it would mean that the drought is of much level. In this study, it was found from the study that in 2015, it was the time when drought was at most level equal to 91.54 or equal to $44975.23 \mathrm{~km}^{2}$. When the results of the study were used to compare with other similar researches such as research on "Application of remote sensing technology for drought monitoring in Mahasarakham Province, Thailand" by Laosuwan et al., (2016), research on "Drought Detection by Application of Remote Sensing Technology and Vegetation Phenology" by Uttaruk \& Laosuwan, (2017), research 
on "Remote Sensing Based Drought Monitoring In The Middle-Part of Northeast Region of Thailand" by Rotjanakusol \& Laosuwan, (2018), research on "Surface Moisture and Vegetation Cover Analysis for Drought Monitoring in the Southern Kruger National Park Using Sentinel-1, Sentinel-2, and Landsat-8" by Urban et al., (2018), it was found that 4 researches had the analysis results in the same direction with that of this study. The result of this study can be used as criteria in making reasonable decision on the Chi watershed area affected by drought, and also can be used to assess the drought area rapidly and reliably. The concerned agencies can apply this method in analyzing the drought area and can apply the result to prepare for plan in preventing and alleviating the drought sustainably in other areas of Thailand further.

\section{R E F E R E N C E S}

Bordi, I., Fraedrich, K., \& Sutera, A. (2009). Observed drought and wetness trends in Europe: An update. Hydrology and Earth System Sciences, 6(3), 3891-3915. Doi:10.5194/hessd-6-38912009

Canedo-Rosso, C., Hochrainer-Stigler, S., Pflug, G., Condori, B., \& Berndtsson, R. (2019). Drought risk in the Bolivian Altiplano associated with El NiñoSouthern Oscillation using satellite imagery data. Natural Hazards and Earth System Sciences, 1-21. Doi:10.5194/nhess-2018-403

Chang, S., Wu, B., Yan, N., Zhu, J., Wen, Q., \& Xu, F. (2018). A Refined Crop Drought Monitoring Method Based on the Chinese GF-1 Wide Field View Data. Sensors, 18(4), 1297. Doi:10.3390/ s18041297

Dutta, D., Kundu, A., Patel, N., Saha, S., \& Siddiqui, A. (2015). Assessment of agricultural drought in Rajasthan (India) using remote sensing derived Vegetation Condition Index (VCI) and Standardized Precipitation Index (SPI). The Egyptian Journal of Remote Sensing and Space Science, 18(1), 53-63. Doi: 10.1016/j.ejrs.2015.03.006

Fensham, R., \& Holman, J. (1999). Temporal and spatial patterns in drought-related tree dieback in Australian savanna. Journal of Applied Ecology, 36(6), 1035-1050. Doi:10.1046/j.1365-2664. 1999.00460.x

Furtuna, P. \& Holobaca, I. (2013). Forest fires study using remote sensing and meteorological indicators. Case study. Geographia Technica, 8(2), 23-37.

Gebrehiwot, T., Veen, A. V., \& Maathuis, B. (2011). Spatial and temporal assessment of drought in the Northern highlands of Ethiopia. International Journal of Applied Earth Observation and Geoinformation, 13(3), 309-321. Doi: 10.1016/j.jag.2010.12.002

Gomasathit T., Laosuwan T., Sangpradit S., \& Rotjanakusol T. (2015). Assessment of Drought Risk Area in Thung Kula Rong Hai using Geographic Information Systems and Analytical Hierarchy Process. International Journal of Geoinformatics, 11(2), 21-27.

Jiao, W., Zhang, L., Chang, Q., Fu, D., Cen, Y., \& Tong, Q. (2016). Evaluating an Enhanced Vegetation Condition Index (VCI) Based on VIUPD for Drought Monitoring in the Continental United States. Remote Sensing, 8(3), 224. Doi:10.3390/rs8030224

Laosuwan, T., Sangpradid, S., Gomasathit, T., \& Rotjanakusol, T. (2016). Application of Remote Sensing Technology for Drought Monitoring in Mahasarakham Province, Thailand. International Journal of Geoinformatics, 12(3), 17-25.

Lines, D., Werner, M., \& Bastiaanssen, W. (2017). The predictability of reported drought events and impacts in the Ebro Basin using six different remote sensing data sets. Hydrol. Earth Syst. Sci., 21, 4747-4765. Doi: 10.5194/hess-21-4747-2017

Nistor, M.M., Man, T.C, Benzaghta, M.A., Nedumpallile Vasu, N., DezsiI, Ş. \& Kizza, R. (2018). Land Cover and Temperature Implications for the Seasonal Evapotranspiration in Europe. Geographia Technica, 13(1), 85-108. DOI: 10.21163/GT_2018.131.09

Park, J., Kim, K., \& Choi, Y. (2008). Application of Vegetation Condition Index and Standardized Vegetation Index for Assessment of Spring Drought in South Korea. IGARSS 2008 - 2008 IEEE International Geoscience and Remote Sensing Symposium. Doi:10.1109/igarss.2008.4779463 
Rimkus, E., Stonevicius, E., Kilpys, J., Maciulyte, V., \& Valiukas, D. (2017). Drought identification in the Eastern Baltic region using NDVI. Earth System Dynamics, 8, 627-637. Doi: 10.5194/esd8-627-2017

Rotjanakusol, T. \& Laosuwan, T. (2018). Remote Sensing Based Drought Monitoring In The MiddlePart of Northeast Region of Thailand. Studia Universitatis Vasile Goldis Arad, Seria Stiintele Vietii, 28(1), 14-21.

Rotjanakusol, T., \& Laosuwan, T. (2019). Drought Evaluation with NDVI-Based Standardized Vegetation Index in Lower Northeastern Region of Thailand. Geographia Technica, 14(1), 118130. Doi:10.21163/GT_2019.141.09

Son, N. T., Chen, C. F., Chen, C. R., Masferrer, M. G., \& Recinos, L. E. (2018). Multitemporal Landsat-MODIS fusion for cropland drought monitoring in El Salvador. Geocarto International, 1-21. Doi:10.1080/10106049.2018.1489421

Thavorntam, W., Tantemsapya, N., \& Armstrong, L. (2015). A combination of meteorological and satellite-based drought indices in a better drought assessment and forecasting in Northeast Thailand. Natural Hazards, 77(3), 1453-1474. Doi:10.1007/s1106 9-014-1501-0

The Department of Agricultural Extension. (2017). Crop Calendar Thailand. Available at http://www.servicelink.doae.go.th/webpage/book\%20PDF/rice/tmie_ rice.pdf. (Accessed on 2 October 2017).

Tucker, C. J. (1979). Red and photographic infrared linear combinations for monitoring vegetation. Remote Sensing of Environment, 8(2), 127-150. Doi:10.1016/0034-4257(79)900 13-0

Urban, M., Berger, C., Mudau, T., Heckel, K., Truckenbrodt, J., Odipo, V. O., Smit, I., Schmullius, C. (2018). Surface Moisture and Vegetation Cover Analysis for Drought Monitoring in the Southern Kruger National Park Using Sentinel-1, Sentinel-2, and Landsat-8. Remote Sensing, 10(9), 1482. Doi:10.3390/rs10091482

Uttaruk, Y., \& Laosuwan, T. (2017). Drought Detection by Application of Remote Sensing Technology and Vegetation Phenology. Journal of Ecological Engineering, 18(6), 115-121. Doi:10.12911/22998993/76326

Wang, J., Rich, P. M., \& Price, K. P. (2003). Temporal responses of NDVI to precipitation and temperature in the central Great Plains, USA. International Journal of Remote Sensing, 24(11), 2345-2364. Doi:10.1080/014311602101 54812

Wang, H., Lin, H., \& Liu, D. (2014). Remotely sensed drought index and its responses to meteorological drought in Southwest China. Remote Sensing Letters, 5(5), 413-422.

Doi: 10.10 80/2150704x.2014.912768

Xiong, X., Wenny, B., \& Barnes, W. (2009). Overview of NASA Earth Observing Systems Terra and Aqua moderate resolution imaging spectroradiometer instrument calibration algorithms and onorbit performance. J. of Applied Remote Sensing, 3(1), 032501. Doi: 10.1117/1.3180864 